Social Council, has undertaken studies on the chemical structure of synthetic substances with morphine-like effects, the relationship between their chemical structure and their analgesic action, and the relationship between the latter and their liability to produce addiction. The Organization has studied the thera- peutic properties and side effects-especially the addiction-producing properties-of 30 drugs of practical importance which have been put on the market as substitutes for morphine and codeine*.

* World Health Organization Chronicle, 13, No. 12 ; Necember 1959.

\title{
MARRIAGE-RATE OF AMERICAN COLLEGE GRADUATES
}

\begin{abstract}
COLLEGE graduates in the United States are now 1 marrying at a much earlier age than their parents. They are having children much sooner, having more children, spacing them much closer together, and seem to be following the general trend of the younger generation by completing their families earlier than their parents.

During 1946-1956, the College Study Group of the Population Reference Bureau, Inc., reported that the fertility of the younger college graduates was higher than that of the graduates of a generation ago (Population Bulletin, Vol. 15, No. 6: Fertility of College Graduates, Pp. 101-116 (Washington, D.C. : Population Reference Bureau, Inc., 1959.) 50 cents). Additional results, gathered in 1955 , have made it possible to measure the degree of these marriage and fertility differences in two college classes, those graduating in 1930 and in 1945. The average age at first marriage in 1955 in the United States was 23 for men and 20 for women. For the graduate class of 1945 , the average age at marriage was 24 years for both sexes and it was 25 years for both sexes for the class of 1930. Ten years after graduation, fewer of the younger graduates remained single: 13 per cent of the men and 10 per cent of the women among the younger graduates, compared with 20 per cent of the men and 27 per cent of the women among the older graduates.
\end{abstract}

The proportion not married ten years after graduation continued to be higher among graduates of Roman Catholic colleges : 20 per cent of the men and 23 per cent of the women in the class of 1945 , compared with 38 per cent of the men and 43 per cent of the women in the class of 1930 .

When the survey was taken in 1955 , the 10 -year women graduates of the class of 1945 who were about mid-way through their family-building years already had a greater average number of children than the 25 -year women of the class of 1930 , who had reached the end of the reproductive span. The men of both classes were parents of still more children than the women in both groups. Although the younger graduates had babies at a faster rate than the older graduates, their contribution to the post-war rise in the birth-rate was not as great as either high school or grade school graduates. The differential birthrate which has concerned eugenicists and others still persists. The 10-year women college graduates did not reach their fertility peak until 1952. Once they started having babies, they continued to have them over a longer period of time than other women of their age. These results confirm the belief that a great change in attitudes towards marriage and family has occurred in the United States, even among college graduates.

\section{PLANT POPULATION AND CROP YIELD \\ BY R. HOLLIDAY \\ Department of Agriculture, University of Leeds}

G RAPHICAL examination of the relation between crop yield and the number of plants per unit area suggests that two distinct types of curve may be obtained. One, typified by work by Engledow ${ }^{1}$ and Hudson ${ }^{2}$ on grain yield in wheat, is approximately parabolic in shape. With this type of curve a certain plant population gives a maximum yield, while greater or less populations give lower yields. Other workers have obtained similar curves in the case of seed, fruit or influorescence yield with other cereals, maize, sorghum, soya beans, peas, tomatoes, hops and both seed and lint yield in cotton.

Work at Leeds with wheat has given, in the case of straw yield, an increasing yield relation to a maximum but with no sign of yield decrease beyond this maximum up to populations established from 4 cwt. of seed per acre. This relation is referred to below as an asymptotic curve. In contrast, the yield of grain in most years showed a maximum at or about populations established from I cwt. of seed per acre. A similar contrast in dry matter yield plant population curves was obtained with pure sowings of perennial ryegrass ${ }^{3,4}$. In the seeding year, with yield resulting from vegetative growth, the curve was asymptotic up to populations established from $160 \mathrm{lb}$./acre; in the following year, where yield was a product of reproductive as well as vegetative growth, the curve showed a maximum at or about populations established from $20 \mathrm{Jb}$. of seed per acre. Donald ${ }^{5}$ in Australia obtained the same kind of contrast with Wimmera ryegrass and sub. terranean clover; the seed-yield curve showed a maximum, while the vegetative yield was asymptotic up to populations of $180 \times 10^{8}$ plants per acre in the case of ryegrass experiments.

Although the range of populations covered are sometimes rather limited, references in the literature would suggest that sugar beet, kale, mangolds, fodder beet, tea and timber yields, all of which are products of vegetative growth, show an asymptotic type of yield-plant population relation. 